\title{
Teaching originality? Common habits behind creative production in science and arts
}

\author{
Marten Scheffer ${ }^{1}$, Matthijs Baas $^{2}$ and Tone K. Bjordam ${ }^{3}$
}

\begin{abstract}
Originality is a prerequisite for world-changing science and arts alike, but it cannot be taught. Or can it? Here, we show that a set of habits that are - surprisingly — shared among successful artists and scientists may catalyze creative output. We reveal three groups of such habits, each corresponding to a cluster of personality traits, shown to be shared by creative artists and scientists. The first habit group "embrace the unexpected" corresponds to the character trait "openness to new experiences" and encompasses tendencies to go ahead without a plan, collect diverse experiences, and take risks. The second group "create conditions for creation" links to the personality trait "autonomous" and encompasses simple habits such as making empty time and carrying a notebook. The third class of habits "break away from dogma" links to the shared personality trait "norm doubting" and stands for a strong drive to escape from established systems and also occasionally destroy part of one's own work to break tunnel vision and start anew. Although personality traits are hard to change, the habits we found hint at techniques or skills that may be taught.
\end{abstract}

Key Words: arts; character traits; creativity; habits; originality; science; teaching; teams

\section{INTRODUCTION}

Arts and sciences may seem opposite poles at first sight. Arts speak to the heart, sciences to the ratio. Yet there are important similarities too. Both are looking for the essence of things and both need creativity and perseverance. Perhaps it is not so surprising then that ground-breaking science and arts often go hand in hand? For instance, Nobel laureates are more likely to practice arts than are members of Academies of Sciences, who are in turn more artistically engaged than the average scientist (Root-Bernstein et al. 2008). One interpretation of this curious correlation could be that practicing arts makes scientists better (Root-Bernstein et al. 2008). Alternatively, the same skills or personality traits that promote scientific excellence could also stimulate artistic production. Indeed, this view is in line with the finding of a metaanalysis revealing that creative scientists and artists have a consistently similar set of personality traits (Feist 1998). For example, compared with the average person, they are more open to new experiences and norm doubting, as well as being autonomous, self-confident, driven, dominant, hostile, and ambitious (Feist 1998). A plausible explanation is that this set of traits makes it more likely that an individual comes up with original things and also develops them further through a tough "justification" phase in spite of possible critiques and failures (Feist 1998). Clearly, there is not much one can do about personality. However, could it be that there are also particular techniques or habits that successful artists and scientists have cultivated, perhaps unconsciously, to facilitate their creative production? As the same set of personality traits makes for creative scientists and artists, would a same set of techniques or habits be found in these professions? Perhaps partly in the form of tacit knowledge that these creative individuals are not even aware of, and consequently do not teach to their students? In search for answers to these questions, we draw upon insights from a series of workshops with practitioners and mentors in arts and sciences (see acknowledgements) and also delve into habitual patterns documented for a range of famously creative minds.

\section{THREE STEPS TO CREATION}

Reflecting on the material we collected, it struck us that there are three sets of shared habits that seem to reflect tacit knowledge on how to produce original creative work. Each of these sets loosely links to a group of personality traits found to be overrepresented in creative scientists and artists, and that may be thought of as promoting three distinct steps in the production of novel work (Fig. 1) (Feist 1998).

\section{Embrace the unexpected}

Although the words creativity and originality may suggest complete novelty, creative production essentially builds on combining existing elements (Allen and Thomas 2011, Kahneman 2011). Chances for novel combinations are arguably better if a rich and diverse collection of elements is available. It is therefore hardly surprising that across numerous studies, "openness to new experiences" stands out as a characteristic personality trait of creative scientists and artists alike (Feist 1998). However, seeking and embracing new experiences also turns out to be a deliberate strategy across the artists and scientists with whom we discussed this theme (listed in the acknowledgements) and throughout documented anecdotes about famous thinkers.

\section{Get moving}

To students, the idea that they should start their own creative career can be daunting. What is the best strategy? Part of this paralyzing situation may be invoked by a misperception of the pathway of professional examples. In hindsight, successful scientists and artists rarely had a masterplan. Rather, most highly creative careers are driven primarily by serendipity and curiosity. As sculptor Francisko Gatizua remarked poetically: "I have been just wandering, picking up stones" (F. Gatizua, personal communication). In fact, being open to such a zigzag path is what, if asked, many of the successful creators recommend upon reflection. For example, Nobel laureate Kenneth Arrow, known for his wide diversity of contributions to economics, had a simple take-home message for attendants at a "wisdom seminar" when it came to the option to change topics in your career: "whenever 
Fig. 1. Three steps in the creative process that are facilitated by distinct character traits, which are relatively difficult to change, but also by sets of practical habits that may be easier to adopt.

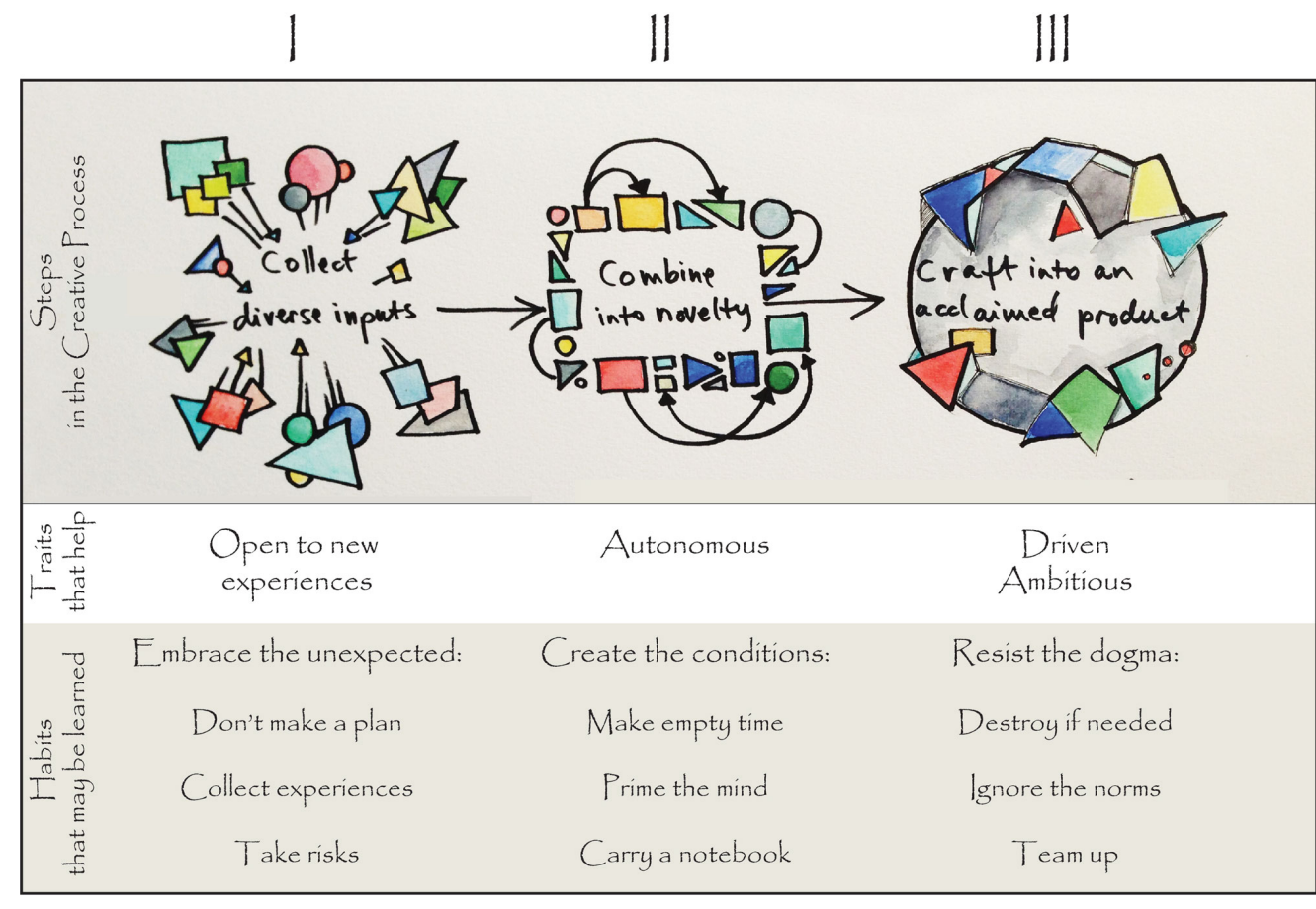

you have the opportunity, always switch" and more in general "subject yourself to new experiences whenever you can." This is not to say that the successful zigzag paths were entirely random of course. Rather, the voyagers had a keen eye for opportunities, for potentially productive directions. Realizing that the road to creative success rarely if ever follows a master plan may seem disappointing, but can at the same time be a relief to students. Do not worry if you do not have a plan. You do not need one. The main thing is to get moving.

\section{Collect diverse experiences}

Embracing the unplanned also has the advantage that one builds a diverse collection of ideas and skills to draw upon. Most of the great contributions to science and arts combine elements developed by predecessors in the field. As we are so often reminded, we are all "standing on the shoulders of giants." However, the best results frequently come from standing firmly on those shoulders, but at the same time, finding some unusual novel associations. For example, a study on the impact of millions of scientific articles showed that the greatest impact came from articles that were well rooted in existing work, but at the same time, made an unusual link to another field (Uzzi et al. 2013). Why are such influential steps so unusual? How could we have more of those? Unbridled curiosity seems the key ingredient. As Kenneth Arrow phrased it: "It is so far from anything I do. I must be interested." (Scheffer 2014). His repeated radical shifts of topic certainly allowed for numerous profoundly innovative ideas. One pragmatic way to prevent getting stuck in the same old dogma, is to team up with people who have different mindsets (Perry-Smith and Mannucci 2017). Much literature points to the power of diversity when it comes creative teams (Page 2008). Perhaps surprisingly, mere cultural or ethnic diversity of coworkers has been shown to correlate to creativity in fashion teams (Godart et al. 2015) and the impact of scientific papers (Freeman and Huang 2014). Importantly, group diversity can work out different ways (Hülsheger et al. 2009) and may only have clear positive effects if the people involved actually value such diversity (Homan et al. 2015).

Take risks

Clearly, the crazy connections that can be so productive are risky too. Who says they will make sense? Are they not too crazy? Arts are clearly less restricted than science, where remote associations are all well as long as they are "correct." This is not easily judged. In a way, mistakes are a calculated risk of innovation, even a sign of daring exploration. As Arrow said "you are not doing very well as a scientist if you are not wrong two-thirds of the time." But he also added "if you are wrong you better find out yourself. Not only because it is more pleasant, but also you learn from it" (Scheffer 2014). Finding out yourself is great, but not easy when it comes to a new field of expertise. Cooperating with solid colleagues from such a field can then be a good insurance against all too obvious mistakes. Still, far-fetched jumps are risky. Scientific training is mostly about reducing the likelihood of mistakes. Therefore, it almost intrinsically promotes risk aversion. In contrast, arts education often has training in risk taking. Much like daring to sail a boat in heavy winds, feeling that ultimately one has the power to get it back under control. Could we train for some more controlled risk taking in science education? Stimulate the wilder intuition-driven explorations alongside cognitive power and techniques to filter out the erroneous from the good results? 


\section{Create conditions for the creative process}

Although a diverse collection of building blocks is important, the power to connect them in novel ways is something else. Numerous anecdotes illustrate that big ideas often come to a wandering mind in solitude. The fact that the personality trait "autonomous" is systematically overrepresented among creative scientists and artists could reflect a predisposition to the acceptance of the solitude that can be so conducive to creative production (Feist 1998). Although being socially rejected can fuel creativity (Kim et al. 2013), solitude may also be a voluntary choice.

\section{Make empty time}

An often-mentioned requirement for the creative process in artists and scientists is simply empty time. The need for episodes without distractions is broadly felt among artists as well as scientists. Indeed, many studies confirm the intuitive idea that distracting sounds and other uncontrollable stressors are negatively associated with creativity (Byron et al. 2010). However, getting away from the crowd physically is not sufficient to isolate the mind from the turmoil of social life and the everlasting stream of information. Digital technologies now allow us to largely avoid "empty" moments. Breaks without distraction or entertainment occur naturally during train rides, meetings or the like, but vanish if we can be constantly engaged, preventing (actual or anticipated) boredom. At the same time, several studies suggest that despite its negative connotation, boredom may provide fertile grounds for innovation (Gasper and Middlewood 2014). This suggests that perhaps many great ideas are now never conceived due to a scarcity of empty time. As a thought experiment, consider the question whether Newton would have developed his groundbreaking idea on gravity if he would have had a smart phone? In a recently uncovered 1752 handwritten document (http://ttp. royalsociety.org/ttp/ttp.html?id=1807da00-909a-4abf-

b9c1-0279a08e4bf2\&type=book), William Stukeley describes how Newton told him how it happened. "After dinner, the weather being warm, we went into the garden and drank tea, under the shade of some apple trees. [Newton] told me, he was just in the same situation, as when formerly, the notion of gravitation came into his mind. It was occasion'd by the fall of an apple, as he sat in contemplative mood. 'Why should that apple always descend perpendicularly to the ground,' thought he to himself. 'Why should it not go sideways, or upwards? But constantly to the earth's centre? Assuredly, the reason is, that the earth draws it. There must be a drawing power in matter." Creativity may generally be boosted during moments of mind wandering (Baird et al. 2012). However, a bit of boredom could be conducive to novelty as it has the extra effect of stimulating exploration as a way of getting rid of this somewhat unpleasant state (Gasper and Middlewood 2014). In times of digital technologies, it may require slightly more effort than before to disconnect, but it is likely worth it. Obviously, the internet is an unprecedented resource of information that can help feed a diverse collection of elements for our associative mind to recombine into novel ideas (Johnson 2010). However, as in all inputs to our mind, there are two sides to the coin: inspiration and distraction. We could see the habit to make empty time as a way to create distraction-free episodes to process the diverse collection of inputs.

\section{But prime the mind}

Completely open-ended empty time can be productive, but many great minds shared the habit of creating seemingly empty time with the explicit goal to solve a problem (Scheffer et al. 2015). Perhaps the best-known example is Darwin, who famously took walks along his especially constructed "thinking path" every day without exception. He would usually have a particular problem in mind that he wanted to process over such walks, and many of us have the same habit of going for a hike or a bike ride with an intentionally primed mind. Several studies now confirm the effectiveness of activities that require little attention, such as walking, for problem solving (Baird et al. 2012, Oppezzo and Schwartz 2014). However, the technique of keeping the mind primed with a problem while doing other activities has been practised systematically long before scientific evidence was found. For instance, Nobel laureate Max Perutz, as his daughter recalls: "whatever he was doing — riding his bicycle, going for walks, deadheading roses - his mind would always be occupied by the latest problem... His approach was that of Isaac Newton who, when asked how he made discoveries, answered: By always thinking about them. I keep the subject constantly before me and wait until the first dawnings open little by little into the full light." (Ferry and Perutz 2007).

\section{Carry a notebook}

Perhaps the simplest of all habits is to always carry a notebook. Ideas often come at inconvenient moments when they cannot be immediately pursued. This can be quite agonizing. For instance, Elizabeth Gilbert describes how rock musician Tom Waits, while driving down the freeway in Los Angeles, "all of a sudden .. hears this little fragment of melody, that comes into his head as inspiration often comes, ... he longs for it, but ... doesn't have a piece of paper, or a pencil, or a tape recorder. So he ... looked up at the sky, and he said, Excuse me, can you not see that I'm driving? Do I look like I can write down a song right now?" (https://www. ted.com/talks/elizabeth gilbert on genius/transcript). Indeed, having something to record an idea can make all the difference, as exemplified by the story of one of the most famous guitar riffs of all times: the beginning of "(I can't get no) satisfaction." Keith Richards woke up at night with that riff in his mind, played it to his cassette tape recorder and fell asleep again. When he woke up in the morning he recalled little at all of the event, but saw the tape ran to the end. Playing it back, he heard the now famous theme followed by 40 minutes of snoring (see the BBC interview with Keith Richard at http://www.bbc.co.uk/music/sevenages/). If it weren't for the recorder, the world would never have enjoyed this piece of rock history.

Although game-changing gems may seem rare, talking to scientists and artists, we found that scarcity of ideas is actually not perceived as a limiting factor. Rather, there may often be too many options, and it is hard to see which are the most promising without taking time to explore them. Most scientists and artists keep notes of ideas as they come, and this provides peace of mind (nothing is lost if you do not immediately pursue it) as well as a rich resource for later use. Darwin came on board the Beagle with little plan at all (Darwin 1958), but kept notes of everything ranging from seemingly unrelated observations to germs of his biggest ideas.

\section{Resist the dogma}

To be original requires taking paths other than the obvious. Two forces work against this. Firstly, the mind has a strong tendency to lock into the patterns it has seen before (Scheffer and Westley 
2007). Secondly, there are social pressures against deviating (Scheffer et al. 2003). In this light, it makes sense that the character trait "norm doubting" is common among creative scientists and artists. Also, the overrepresentation of traits such as "hostile" and "dominant" may be interpreted as reflecting the force needed to defend deviating ideas and swim against the mainstream (Feist 1998). Although innate character traits will be important, deliberate efforts to escape the attracting force of the established permeate accounts from artists and creative scientists alike.

\section{Destroy your work if needed}

Like anyone else, Scientists and artists easily fall in love with an idea, and although love is strong, it also blinds, preventing exploration of alternative paths (Chamberlin 1897). Moreover, much is invested during the sometimes lengthy process of creation of an art piece or scientific article, and as sunk costs rise, it becomes increasingly tempting to remain on the same track rather than giving it up (Arkes and Ayton 1999). We were surprised to learn that artists and scientists have independently come to recognize and deal with the challenge of tunnel vision in similar ways. For instance, in addition to noting that one should always remain doubtful and critical, some of the artists have the habit of partly destroying their work when they are close to finishing to allow a refreshing essential rearrangement to bring it closer to the essence they might have lost sight of in the process of refinement. The famous Picasso quote "Every act of creation is first an act of destruction" hints at the same (Mauzy et al. 2003). This artist habit is quite similar to the habit of many scientists (author MS is an example) of breaking up an almost finished scientific article to allow for a fresh take on it, escaping the seductive tunnel created by one's earlier formulations.

\section{Ignore the norms}

In addition to the risk of personal lock-in, there are formidable social pressures that may smother novelty. Artists sometimes stress the risk of academia. Some artists chose to live in utterly isolated places in nature, not only to create solitude and be close to sources of inspiration, but also to simply be away from the suffocating sense of critique by "the system." Paradoxically, this includes the pressure to be original for the sake of being original with the risk of evoking meaningless avant-garde work, paralleled by the worry in science that perceived novelty is often rewarded at the expense of quality (Vinkers et al. 2015). As an antidote, some scientists call for "slow science" away from the turbulent flow of hypes (Alleva 2006), whereas artists often mention the need to be entirely open and deeply perceptive to intuition. The urge to escape a dogmatic system is particularly prominent in the arts. However, the paralyzing effect of dogma as the enemy of scientific progress has also been known for centuries. In fact, it is a central theme in the work of 16th century philosopher Baruch Spinoza (Spinoza 2006). Several well-known scientists are known for deliberately avoiding the carved tracks. For instance, Nobel laureate Richard Feynman refused to use the standard mathematical tools and instead invented an entirely new kind of graph to explore his ideas. Also, he stayed away from digging too deeply into the existing literature (Gleick 2011).

\section{Team up}

Obviously, going against the ruling dogma can bring great rewards but may also have high social and professional costs. Spinoza himself was expelled by his Jewish community for thinking outside of the permitted box (Spinoza 2006). More recently, when Daniel Shechtman discovered the liquid crystals (that eventually earned him a Nobel prize), his unconventional finding caused such dismissal and ridicule that his boss asked him to leave the research group (Clery 2011). One way to arm oneself psychologically against repressive forces of establishment can be to team up. Just as artist collectives such as COBRA can help to keep the spirits up in the struggle to break away from the ruling paradigms, a team of coauthors can sometimes help prevent giving up in science.

\section{PROSPECT}

Clearly there are limits to what simple habits can do. Openness to new experiences, autonomy, self-confidence, and a tendency to doubt the ruling norms may be largely inherent character traits that are hard to change. Still, some of the habits that are consciously or unconsciously cultivated by successful artists and scientists may well help to give the small nudge needed by young students to pull through. However, thinking about bringing this into practice brings up some obvious questions: How do we deal with tensions and paradoxes in the advice? How may those ideas be brought to the classroom? How could we get more crosslearning between the arts and the sciences? Here, we articulate some of these challenges to stimulate further thinking.

\section{Tensions and paradoxes}

Although the individual ideas may seem to make sense, it may have struck you that there are some inherent tensions between them. First of all, there are pros and cons to teaming up (Sawyer 2008). There is the risk of "group think" smothering creativity (Esser 1998). Composing a diverse team may ward off this risk. Diverse teams can bring up more ideas and perspectives, and complementarity between inherent character traits of different members can facilitate going through all stages of the creative process from conception to implementation (Page 2008, Meredith Belbin 2011). In addition, the group size itself may have negative effects too. For instance, a recent study suggests that, in science, novelty shows an inverse U-shaped relation to group size (number of authors on a paper), with the decline at larger group sizes possibly resulting from coordination problems in sorting out the best ideas (Lee et al. 2015).

Another obvious tension exists between staying away from dogma and "reinventing the wheel." Commenting on Nobel laureate Feynman's habit of neglecting the literature, fellow physicist Sidney Coleman remarked, "Those other guys are not a collection of yo-yos. Sometimes it would be better to take the recent machinery they have built and not try to rebuild it," and stated that Feynman got away with it just "because he was so goddamn smart" (Gleick 2011). However, Feynman clearly had given the trade-off some thought himself too as reflected in his remark "Maybe that's why young people make success. They don't know enough. Because when you know enough it's obvious that every idea that you have is no good." (Gleick 2011). A third obvious tension exists between the need for diverse inputs and the requirement for undisturbed solitude.

Clearly, part of these apparent incompatibilities may be resolved by compartmentalization of the three phases of creative production (Fig. 1). Not only do different phases of creative production benefit from different personality traits and skills 
(Perry-Smith and Mannucci 2017), they will also work best in different settings. Although the collecting phase (I) is catalyzed by inputs from encounters with diverse persons, reading different literatures and surfing the web, the combining phase (II) may thrive better on solitary walks, and the crafting phase (III) may benefit from laborious desk work. One wants to be alone in the combining phase (II), but a broader group may be good in the collecting phase (I), and again later to prevent one from coming up with a reinvention of the wheel, and pull the project through a tough crafting phase (III) of finalizing an accepted result against the mainstream. Interestingly, many famous artists and scientists seem to have developed daily routines that allowed the different conditions to alternate systematically, producing a steady rhythm of time slots for mind wandering, desk work, and socializing (Currey 2013).

\section{Finding a partner in the arts}

Perhaps the most important paradox is the one brought up in the title. Could we actually teach originality? Is there any way in which we might bring these habits to the classroom or lab? Could we intervene at the college or graduate level, or is earlier intervention necessary as well? What kind of intervention would be needed? Is simple awareness enough, or should there be active training? There are good arguments for a thorough rethink of our educational system, with active training complementing metathinking about creativity throughout the curriculum (Costa and Kallick 2008). Creative thinking is the core business of scientists, and yet they rarely give it much thought (Scheffer 2014, Scheffer et al. 2015). This is remarkably different in the arts, where nurturing the creative process is an integrated part of education. Obviously, we could learn a lot by teaming up, and this is not only true when it comes to teaching originality. Thinking about it, the prevailing segregation of arts and sciences is indeed unnatural and unfortunate.

The convergence of personality traits and deliberate strategies to foster the creative process across artists and scientists may seem remarkable. Art and science are so different in appearance, yet so similar in the making. So, why are the two giants of the human mind so separated? The names of many of the respected ancient academies of sciences reflect a union of arts and sciences, once considered natural. As E.O. Wilson argued, we are in search for the essence of the same world, but somewhere lost the powerful unity of thinking across arts and sciences from the renaissance (Wilson 1995). The development since those days has been explosive, and sciences have become a powerful aid to modern society in many ways. Nevertheless, science is in some sense also stuck. We face entirely new global challenges as a result of "the great acceleration." The boost of technology together with the explosion of the world population have caused humans to entirely dominate the planet, and we are undeniably approaching some boundaries (Rockström et al. 2009). Quoting a 2011 editorial in the journal The Economist: "humans have changed the earth, now they have to change the way they think about it" (The Economist 2011). That sounds reasonable, but is easier said than done. Some serious out of the box thinking involving the broadest possible collection of minds may be no luxury. We do not usually pay much attention to training skills for this in academia (Scheffer 2014). However, handing a new generation the best possible tools for finding novel solutions to the challenges that humanity faces is the least we can do. If there is one take-home message from the discussions with artists and scientists we had (see acknowledgements), it is that we can learn a lot from each other's approaches in this respect. Institutions are often a barrier rather than a bridge to innovation. Nonetheless, it would pay to push for a reunion of arts and sciences in our academies and universities. It might be seen as a luxurious wish, but we would argue that, in fact, we cannot afford the luxury of isolating them anymore.

Responses to this article can be read online at: http://www.ecologyandsociety.org/issues/responses. $\mathrm{php} / 9258$

\section{Acknowledgments:}

This essay draws upon discussions on a series of workshops hosted at the SARAS institute, the Royal Swedish Academy of Sciences and the Royal Netherlands Academy of Arts and Sciences involving, among others, the scientists Kenneth Arrow, Mariana Meerhof, Nestor Mazzeo, Osvaldo Sala, Ana Parma, Jorge Marcone, Jordi Bascompte, Henrik Österblom, Pablo Marquet, Eduardo Viola, Terese Lindahl, Milena Holmgren, Reinette (Oonsie) Biggs, and Lisa Deutsch; and artists Laurie-Beth Clark, Michael Peterson, Jesse-Lee Kercheval, Carel Kraayenhof, Miguel van Esso, Angela Leible, and Francisko Gazitua. Discussions with the "surprise group" Frances Westley, Carl Folke, and Stephen Carpenter have been particularly important in shaping the views on conditions for scientific novelty.

\section{LITERATURE CITED}

Allen, A. P., and K. E. Thomas. 2011. A dual process account of creative thinking. Creativity Research Journal 23:109-118. http:// dx.doi.org/10.1080/10400419.2011.571183

Alleva, L. 2006. Taking time to savour the rewards of slow science. Nature 443:271--271. http://dx.doi.org/10.1038/443271e

Arkes, H. R., and P. Ayton. 1999. The sunk cost and Concorde effects: are humans less rational than lower animals? Psychological Bulletin 125:591-600. http://dx.doi.org/https://doi. org/10.1037/0033-2909.125.5.591

Baird, B., J. Smallwood, M. D. Mrazek, J. W. Y. Kam, M. S. Franklin, and J. W. Schooler. 2012. Inspired by distraction: mind wandering facilitates creative incubation. Psychological Science 23:1117-1122. http://dx.doi.org/10.1177/0956797612446024

Byron, K., S. Khazanchi, and D. Nazarian. 2010. The relationship between stressors and creativity: a meta-analysis examining competing theoretical models. Journal of Applied Psychology 95:201-212. http://dx.doi.org/10.1037/a0017868

Chamberlin, T. C. 1897. The method of multiple working hypotheses. Journal of Geology 5:837-848. http://dx.doi. org/10.1086/607980

Clery, D. 2011. Once-ridiculed discovery redefined the term crystal. Science 334:165-165. http://dx.doi.org/10.1126/ science.334.6053.165 
Costa, A. L., and B. Kallick. 2008. Learning and leading with habits of mind: 16 essential characteristics for success. ASCD, Alexandria, Virginia, USA.

Currey, M. 2013. Daily rituals: how artists work. Knopf, Random House, New York, New York, USA.

Darwin, C. 1958. Selected letters of evollution and origin of species - with an autobiographical chapter. F. Darwin, editor. Dover Publications, Mineola, New York, New York, USA.

Esser, J. K. 1998. Alive and well after 25 years: a review of groupthink research. Organizational Behavior and Human Decision Processes 73:116-141. http://dx.doi.org/10.1006/ obhd.1998.2758

Feist, G. J. 1998. A meta-analysis of personality in scientific and artistic creativity. Personality and Social Psychology Review 2:290309. http://dx.doi.org/10.1207/s15327957pspr0204 5

Ferry, G., and M. Perutz. 2007. The secret of life. Cold Spring Harbor Laboratory Press, Cold Spring Harbor, New York, USA.

Freeman, R. B., and W. Huang. 2014. Collaborating with people like me: ethnic co-authorship within the US. National Bureau of Economic Research, Cambridge, Massachusetts, USA. http://dx. doi.org/10.3386/w19905

Gasper, K., and B. L. Middlewood. 2014. Approaching novel thoughts: understanding why elation and boredom promote associative thought more than distress and relaxation. Journal of Experimental Social Psychology 52:50-57. http://dx.doi. org/10.1016/j.jesp.2013.12.007

Gleick, J. 2011. Genius: the life and science of Richard Feynman. Vintage Books, New York, New York, USA. http://dx.doi. org/10.1063/1.2809877

Godart, F. C., W. W. Maddux, A. V. Shipilov, and A. D. Galinsky. 2015. Fashion with a foreign flair: professional experiences abroad facilitate the creative innovations of organizations. Academy of Management Journal 58:195-220. http://dx.doi. org/10.5465/amj.2012.0575

Homan, A. C., C. Buengeler, R. A. Eckhoff, W. P. van Ginkel, and S. C. Voelpel. 2015. The interplay of diversity training and diversity beliefs on team creativity in nationality diverse teams. Journal of Applied Psychology 100:1456. http://dx.doi. org/10.1037/ap10000013

Hülsheger, U. R., N. Anderson, and J. F. Salgado. 2009. Teamlevel predictors of innovation at work: a comprehensive metaanalysis spanning three decades of research. Journal of Applied Psychology 94:1128. http://dx.doi.org/10.1037/a0015978

Johnson, S. 2010. Where good ideas come from: the natural history of innovation. Penguin, London, UK.

Kahneman, D. 2011. Thinking, fast and slow. Farrar, Straus and Giroux, New York, New York, USA.

Kim, S. H., L. C. Vincent, and J. A. Goncalo. 2013. Outside advantage: can social rejection fuel creative thought? Journal of Experimental Psychology: General 142:605. http://dx.doi.org/ https://doi.org/10.1037/a0029728
Lee, Y.-N., J. P. Walsh, and J. Wang. 2015. Creativity in scientific teams: unpacking novelty and impact. Research Policy 44:684697. http://dx.doi.org/10.1016/j.respol.2014.10.007

Mauzy, J., R. A. Harriman, and R. Harriman. 2003. Creativity, inc: building an inventive organization. Harvard Business Press, Cambridge, Massachusetts, USA.

Meredith Belbin, R. 2011. Management teams: why they succeed or fail. Human Resource Management International Digest volume 19, issue 3. Emerald Group Publishing Limited, Bingley, UK.

Oppezzo, M., and D. L. Schwartz. 2014. Give your ideas some legs: the positive effect of walking on creative thinking. Journal of Experimental Psychology: Learning Memory and Cognition 40:1142-1152. http://dx.doi.org/10.1037/a0036577

Page, S. E. 2008. The difference: how the power of diversity creates better groups, firms, schools, and societies (new edition). Princeton University Press, Princeton, New Jersey, USA.

Perry-Smith, J. E., and P. V. Mannucci. 2017. From creativity to innovation: the social network drivers of the four phases of the idea journey. Academy of Management Review 42:53-79. http:// dx.doi.org/10.5465/amr.2014.0462

Rockström, J., W. Steffen, K. Noone, Ã. Persson, F. S. Chapin, E. F. Lambin, T. M. Lenton, M. Scheffer, C. Folke, H. J. Schellnhuber, B. Nykvist, C. A. De Wit, T. Hughes, S. van der Leeuw, H. Rodhe, S. Sörlin, P. K. Snyder, R. Costanza, U. Svedin, M. Falkenmark, L. Karlberg, R. W. Corell, V. J. Fabry, J. Hansen, B. Walker, D. Liverman, K. Richardson, P. Crutzen, and J. A. Foley. 2009. A safe operating space for humanity. Nature 461:472475. http://dx.doi.org/10.1038/461472a

Root-Bernstein, R., L. Allen, L. Beach, R. Bhadula, J. Fast, C. Hosey, B. Kremkow, J. Lapp, K. Lonc, and K. Pawelec. 2008. Arts foster scientific success: avocations of Nobel, National Academy, Royal Society, and Sigma Xi members. Journal of the Psychology of Science and Technology 1:51-63. http://dx.doi. org/10.1891/1939-7054.1.2.51

Sawyer, K. 2008. Group genius: the creative power of collaboration. Basic Books, New York, New York, USA.

Scheffer, M. 2014. The forgotten half of scientific thinking. Proceedings of the National Academy of Sciences of the United States of America 111:6119. http://dx.doi.org/10.1073/pnas.1404649111

Scheffer, M., J. Bascompte, T. K. Bjordam, S. R. Carpenter, L. B. Clarke, C. Folke, P. Marquet, N. Mazzeo, M. Meerhoff, O. Sala, and F. R. Westley. 2015. Dual thinking for scientists. Ecology and Society 20(2):3. http://dx.doi.org/10.5751/es-07434-200203

Scheffer, M., and F. R. Westley. 2007. The evolutionary basis of rigidity: locks in cells, minds, and society. Ecology and Society 12 (2):36. http://dx.doi.org/10.5751/es-02275-120236

Scheffer, M., F. Westley, and W. Brock. 2003. Slow response of societies to new problems: causes and costs. Ecosystems 6:493502 .

Spinoza, B. 2006. The essential Spinoza: ethics and related writings. Hackett Publishing, Indianapolis, Indiana, USA. 
The Economist. 2011. Welcome to the Anthropocene. Editorial, The Economist, 28 May 2011. [online] URL: http://www. economist.com/node/18744401

Uzzi, B., S. Mukherjee, M. Stringer, and B. Jones. 2013. Atypical combinations and scientific impact. Science 342:468-472. http:// dx.doi.org/10.1126/science. 1240474

Vinkers, C. H., J. K. Tijdink, and W. M. Otte. 2015. Use of positive and negative words in scientific PubMed abstracts between 1974 and 2014: retrospective analysis. BMJ 351:h6467. http://dx.doi. org/https://doi.org/10.1136/bmj.h6467

Wilson, E. O. 1995. Consilience: the unity of knowledge. Abacus Books, London, UK. 